Article

\title{
Leadership and Learning: Conceptualizing Relations between School Administrative Practice and Instructional Practice
}

\author{
James P. Spillane
}

School of Education and Social Policy, Northwestern University, 2120 Campus Drive, Evanston, IL 60208, USA; E-Mail: j-spillane@northwestern.edu

Academic Editors: Kenneth Leithwood and Jingping Sun

Received: 9 February 2015 / Accepted: 3 April 2015 / Published: 13 April 2015

\begin{abstract}
In this paper I argue that one problem we face in understanding relations between school leadership and student learning is that core constructs in our work are often variably and weakly defined. Loose constructs pose problems because they contribute to fuzzy research, especially if constructs such as school leadership, management, or even instruction are weakly (or never explicitly) defined and operationalized. Fuzzy conceptualization makes comparing across studies, essential to the development of a robust empirical knowledge base, difficult if not impossible. Arguing that a critical but often overlooked challenge in studying relations between school administration and student learning is conceptual in nature, I begin by conceptualizing school administration and instruction from what I refer to as a distributed perspective, using theoretical work in distributed and situated cognition, activity theory, and micro sociology. I show how conceptualizing phenomena under study in particular ways shapes how we might frame and hypothesize relations among these phenomena. I contrast a distributed conceptualization with more conventional, individually focused conceptualizations of both phenomena. I then consider the entailments of my conceptualization of the two core phenomena for framing relations between them.
\end{abstract}

Keywords: School Leadership; Instructional Reform; School Improvement

\section{Introduction}

Research studies, research syntheses, and meta-analyses show that school leadership and management are important in maintaining instructional quality, leading instructional improvement, and 
realizing valued student outcomes. Though establishing strong causal inferences has proven difficult, an ever-expanding empirical knowledge base suggests that school leadership and management matter for classroom instruction and student learning [1-11]. Still, there is work to be done not only in establishing stronger causal inferences about these relations but, equally if not more important, explicating how school leadership and management actually influence instruction and student learning. Opening up the black box between school leadership and management (henceforth referred to as school administration) and student learning is essential if research knowledge is to inform practice in schools and school systems.

In this paper, I focus on one critical challenge to better understanding relations between school administration and student learning. I argue that one problem we face is that core constructs in our work are often variably and weakly defined. While variability is inevitable and indeed potentially generative for scholarship, it is problematic when coupled with poorly defined constructs. Loose constructs pose problems for all of us contributing to fuzzy research, especially if constructs such as school leadership, management, or even instruction are weakly (or never explicitly) defined and operationalized. Fuzzy conceptualization makes comparing across studies, essential to the development of a robust empirical knowledge base, difficult if not impossible. Fuzzy conceptualizations can also contribute to a false sense of agreement among practitioners and policymakers as they use the same words (e.g., leadership, teaching) to denote distinctly different understandings of these phenomena. Hence, I argue that a critical but often overlooked challenge in studying relations between school administration and student learning is conceptual in nature.

Even when scholars use similar conceptual frameworks, such as a distributed framework, there are often substantial differences in how they define constructs and operationalize them. Transparency enables us as a field to compare and contrast the findings from separate studies. Consider three different studies by way of example, all using a distributed framework and all exemplifying the explicitness and transparency I am arguing for in this paper with respect to conceptualization and study operations. First, Leithwood and colleagues, building on Peter Gronn's work on "holistic forms" of distributed leadership [12], conceptualize how leadership is distributed in schools by focusing on the extent to which the performance of leadership functions is consciously aligned across different sources of leadership and propose four study operations: planful alignment, spontaneous alignment, spontaneous misalignment and anarchic misalignment [13]. Second, to model distributed leadership effects on student learning, Heck and Hallinger conceptualize leadership as "forms of collaboration practiced by the principal, teachers, and members of the school's improvement team" [4]. They developed study operations to tap into three aspects of distributed leadership in schools and measured these using survey items focused on teachers' perceptions of leadership as exercised by different sources - collaborative decision-making about educational improvement; the extent to which school leadership emphasized school governance that empowered staff and students; emphasis school leaders placed on participation in efforts to evaluate the school's academic development. Third, Camburn and colleagues surveyed teachers and formally designated school leaders in 120 elementary schools using a distributed framework, operationalizing leadership as a set of organizational functions. The study asked participants about leadership functions that fell into one of three categories-instruction, building management, and boundary spanning - and examined how responsibility for different leadership functions was arrayed by formally designated leadership position [14]. These three studies 
exemplify the sort of transparency in conceptual and study operation work that is essential for comparing across studies in efforts to measure and explicate the "how" of relations between administrative practice and student learning. They also underscore how merely invoking a conceptual framework in our research is necessary but insufficient; it is also essential that we specify our constructs and our study operations for these constructs.

In this paper, I show how conceptualizing phenomena under study in particular ways shapes how we might frame and hypothesize relations among these phenomena. Conceptual (and practical) frameworks are similar to scaffolding that builders use to repair a building in that they give us access to particular aspects of phenomena while leaving other aspects in the background and often inaccessible [15]. By drawing on work in different theoretical traditions, conceptual frameworks serve as "a skeletal structure of justification" (rather than "structure of explanation") enabling us to frame and focus our exploration of phenomena such as school administrative practice and instruction [16]. It is not surprising that studies conceptualizing the same phenomena in different ways can reach different or even conflicting conclusions about the nature of relations among these phenomena. Hence, explicitly defining and operationalizing core constructs in our research is essential so that we can systematically compare empirical findings in time and across time.

Rather than focusing on student achievement and/or attainment, I focus on instruction, as it is the most proximal cause of students' opportunities to learn that schools and school systems can manipulate. Student learning is critical, but teachers and school leaders cannot learn for students; students must do the learning themselves [17]. What school leaders and teachers can do is create more or less rich opportunities for students to learn through instruction. Some readers may disagree pointing to, among other things, a strong association between students' achievement/attainment and their socio-economic circumstances and/or cultural backgrounds. Or, readers might point to empirical evidence suggesting that the effect sizes of school level variables such as school norms and climate (e.g., academic press) rival the effect size of classroom instructional approach. But, these objections are a function of conceptualizing instruction too narrowly, confined to classrooms and/or focused exclusively on cognitive or academic matter. However, instruction extends beyond the classroom to students' experience in schools more broadly in the hallways, lunchrooms, and before and after school start and end times. Further, as most school leaders and teachers will attest, instruction is about more than academic or cognitive matters; it is also fundamentally about social, emotional and affective matters. It involves how children's ideas and ways of being are treated inside schools. While schools and school systems cannot directly create more equitable societies (that being a matter for other public policy sectors such as taxation policy), how they treat students through instruction inside and outside the classroom do matter for student learning and by extension their achievement and attainment [18-23]. In short, how we conceptualize instruction has fundamental entailments for studying relations between school administration and student learning: Conceptualizing instruction narrowly as purely a classroom or cognitive matter necessitates different research designs than conceptualizations that attempt to capture the multi-facet and multi-place nature of instruction.

I begin my argument by conceptualizing school administration and instruction from what I refer to as a distributed perspective, using theoretical work in distributed and situated cognition, activity theory, and micro sociology. I contrast a distributed conceptualization with more conventional, individually focused conceptualizations of both phenomena. I see this work as essential to developing 
a conceptual (or practical) framework for studying relations between these two social phenomena. Next, based on my conceptualization of school administrative practice and instructional practice, I sketch a framework for thinking about relations among them. To do so, I draw on social theory from several traditions and consider the entailments of taking a distributed perspective for developing a framework to focus empirical observation and measurement of relations between school administration and instruction. Third, I briefly discuss moving beyond conceptualization to developing study operations in order that we might observe and measure relations between school administration and instruction in the world under experimental (including quasi experimental) or "natural" conditions. I conclude with some reflections on the importance of conceptual work for research that purports to examine the strength and nature of relations between school administration and student learning.

\section{Conceptualizing School Leadership and Management: A Distributed Perspective}

For readability purposes, I use school administration or administrative practice to refer to school leadership and management. Leadership involves a social influence interaction in an effort to initiate change and transform existing ways of working in order to achieve some goal [24,25]. Definitions of leadership are abundant in the literature [25]. The onus is on researchers to be clear about our "working" definitions of leadership. This is not purely an academic or theoretical matter, but a very practical matter indeed whether we are researchers or practitioners. In my working definition, leadership refers to activities tied to the core work of an organization that are designed to influence the motivation, knowledge, affect, or practice of organizational members or that are understood by organizational members as intended to influence their motivation, knowledge, affect, or practice [26]. Though often portrayed as different and sometimes even as opposites, management and leadership are close relatives. Management is about maintaining current ways of doing things [24]. Though analytically distinguishable, management and leadership work in tandem in day-to-day practice in organizations. School leaders are expected not only to lead improvement in instruction in their schools but also maintain the quality of instruction over time. Hence, it is critical to attend to both leadership and management referred to in this paper as school administrative practice.

For over a decade, several scholars have advanced a distributed perspective that re-conceptualizes school administration for research and development work [27,28]. Based on theoretical work on distributed and situated cognition, activity theory, and micro sociology, these scholars argue for attention to leadership and management as practice [29]. Scholars of human activity working in several traditions argue for attention to activity systems that take into account people interacting with one another and their environment. Hutchins [30], for example, argues for understanding the task of landing a plane by taking the cockpit rather than the pilot's mind as the unit of analysis. The cockpit, what Hutchins' terms a "socio-technical system," includes not only the pilot and co-pilot but also the instrumentation and tools (e.g., several instruments that measure speed) that enable them in the activity of landing the plane. These features of the situation are not merely "aides" to the pilots' cognition; rather, human activity is "stretched over" actors and aspects of their situation because what the pilots notice, how they interpret what they notice, and how they negotiate with one another the meanings of what they noticed is not only a function of their individual mental scripts but also their interactions and the tools that enable (and constrain) their joint work. Hutchins' notion of a "socio-technical system" suggests that in studying school administrative practice we must attend not simply to school leaders' 
intra-mental models and behavior but also to inter-mental models-models or representations of learning, teaching, and achievement contained in the material and abstract tools that school staff use to interact with one another. Scholars from various traditions use different constructs in shifting the unit of analysis from individual activity to people interacting with one another in a system including (but not limited to) "communities of practice" [31,32], "activity systems" [33,34], "social worlds" and "social forms" [35].

Framed from a distributed perspective, school administrative practice is the key unit of analysis [26,29]. Researchers have studied leadership behavior for a half-century or more [36,37], usually observing what individual leaders (typically the school principal) do, and identifying more or less efficacious behaviors. From a distributed perspective, however, framing practice as behavior fails to recognize its distributed nature because practice is constituted in the interactions rather than in the action of an individual. A distributed perspective, then, conceptualizes practice in a very particular way: practice is not just about the actions of individual leaders, though they are clearly relevant; it is fundamentally about interactions among leaders and among leaders and followers [29]. And, leaders not only influence followers but followers also influence leaders in these interactions [24,38]. Actions, though necessary, are insufficient in the study of administrative practice because practice is framed as a product of the interactions among leaders and followers. In this framing, school staff (e.g., principal, curriculum specialist or teacher), and indeed school stakeholders more broadly (e.g., parents, students, community members), can move in and out of the leader role depending on the activity or situation (see Figure 1). In this paper I use the term practice to refer to social interactions, not individual behavior.

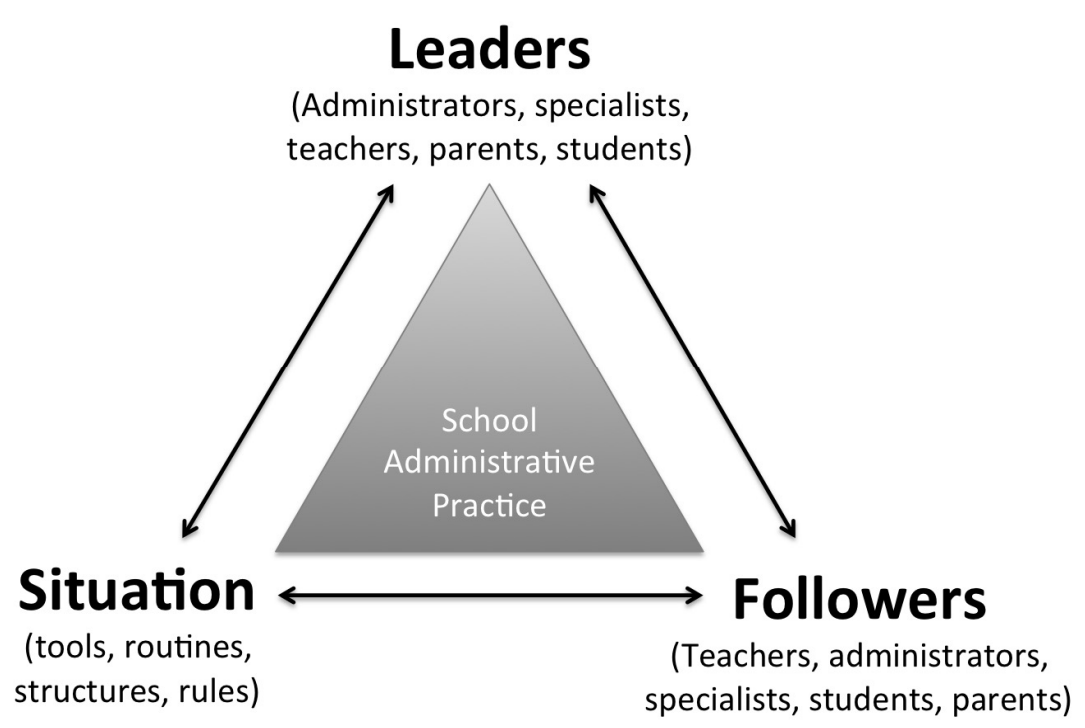

Figure 1. School Administration Practice.

As evidenced in Hutchins' "socio-technical system", the situation also matters because people don't interact directly with one another; their interactions are made possible by "social structure"-everyday, often taken for granted, aspects of the situation including, but not limited to, language, social norms, organizational routines, work procedures, rules, and tools [30]. Aspects of the situation frame and focus interactions among school staff and stakeholders thereby enabling and constraining school 
administrative practice. In this way, the situation defines school practice from the inside; it is internal to practice as depicted in Figure 1.

Some readers will note that scholars have long taken the situation into account in scholarship on organizational administration. While this is correct, scholars more often than not treat aspects of the situation as external to practice, not as core constituting or defining elements of practice. In doing so, aspects of the situation are cast as independent variables that influence practice by muting or enhancing the effects of administrative practice on an outcome or dependent variable (e.g., student achievement) or by strengthening or weakening the influence of a leader's behavior on followers. In treating the situation as one of the three core constituting elements of administrative practice (along with leaders and followers), aspects of the situation do not simply affect what people do or plan to do but rather define practice from inside, enabling and constraining social interactions among people. Aspects of the situation are the medium for human interactions framing and focusing how leaders and followers interact and thereby defining administrative practice. In this view, aspects of the situation do not simply enhance or mute the effects of administrative practice on some outcome nor simply strengthen or weaken the influence of leaders' behavior: Rather, aspects of the situation are the vehicle for interacting and thereby define practice. Figure one captures the core constituting nature of the situation by affording it a position equivalent to leaders and followers rather than casting it in some secondary role [29,39].

Framing school administrative practice from a distributed perspective allows for the fact that multiple individuals in addition to the school principal are involved with the work [13,14,26,40,41]. In addition to other formally designated school leaders, a distributed perspective allows for the possibility that individuals without any formal leadership designation may be responsible for and engaged in leading and managing practice. Taking a distributed perspective involves understanding how different configurations of school staff and school stakeholder in interaction, by design or default, constitute the practice of leading and managing instruction. Such considerations press us to examine various factors, from the division or duplication of school administrative responsibilities to whether and how those who have a hand in the work do or do not complement one another.

\section{Conceptualizing Instruction as a Collective, Situated, and Distributed Practice}

As noted above, instruction is the most proximal means that schools have for influencing students' opportunities to learn and by extension student learning. Instruction is often conceptualized as what the teacher does, a solo practice, roughly equivalent to a teacher's behavior in the classroom. Indeed, there is a long tradition of research that examines the relations between teacher or teaching behaviors and students' learning, one of the most prominent being the process-product research tradition $[42,43]$. Process-product research examined relations between what teachers do and student learning, mostly measured in terms of student performance on standardized achievement tests. Scholars observed and measured discrete teaching behaviors (e.g., teachers use of praise, the length of wait time teachers allowed for a student to answer), summed variables across situations, and then correlated teaching behaviors with student achievement. While acknowledging its contribution to our understanding of teaching, process-product research has been criticized on several levels, including its often a-theoretical approach [42,44-47]. 
Other scholars have conceptualized instruction differently, recognizing and foregrounding its distributed, situated, and collective nature as a practice [17,48-52]. Deborah Ball and David Cohen's conceptual work on instruction is particularly informative here: They argue for conceptually framing teaching as a practice that is coproduced by teachers and their students on and with particular intellectual (e.g., mathematics, language arts) and physical material such as curriculum and texts $[17,48]$. Framing instruction this way, it is no longer just a function of the teachers' skill and knowledge but also a function of students' knowledge and skill and indeed key aspects of the situation such as the intellectual material being taught and learned and the materials that are being used for instruction. Teachers and students in interaction with, and about, particular material co-produce teaching; Cohen and Ball refer to these three core constituting elements together as the instructional unit (Figure 2) [48].

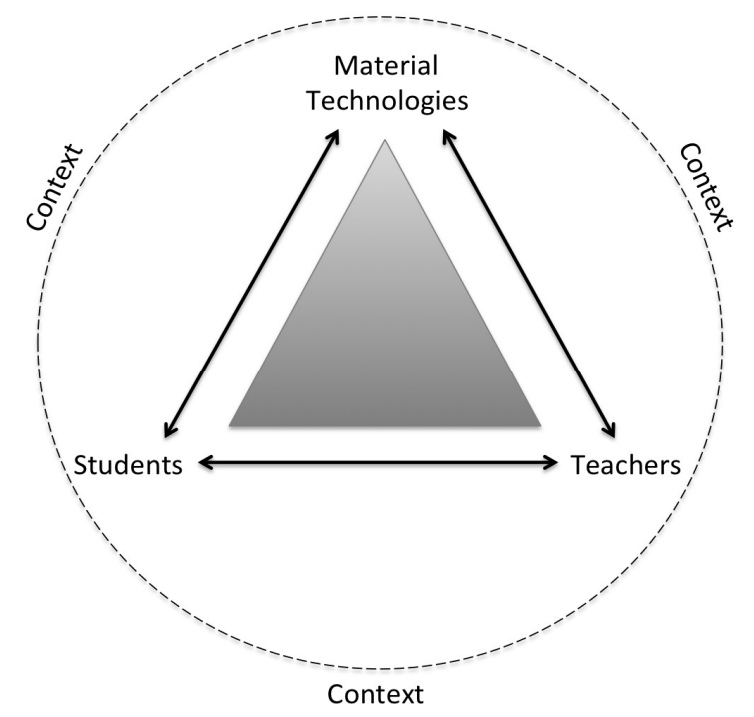

Figure 2. The Internal Dynamics of Instructional Units. ${ }^{1}$

Framed in terms of the three constituting elements of the instructional unit, instruction is not equivalent to a teacher's behavior or a function of her/his knowledge and skill. Instead, instruction takes form in the interaction of teachers and students about particular intellectual material and with aspects of the situation. All three elements - teachers, students, and materials - are mutually constitutive of instruction. Accordingly, instructional capability "is a function of the interaction among elements of the instructional unit, not the sole province of any single element" [48]. By extension, then, instructional capability is not fixed but dependent on the particular instance of instruction. Conceptualizing instruction as a distributed practice acknowledges that the nature of practice and indeed the quality of practice is a function not simply of any one element but of these elements in interaction. The nature of instructional practice can look quite different even with the same teacher but different students and/or different materials.

As depicted in Figure 2, context is also a key consideration with respect to instructional practice. Specifically, aspects of the situation, especially the immediate school situation, beyond those captured by the material/technologies element of the instructional unit influence instructional practice. Students'

1. Adapted from Cohen \& Ball [48]. 
experiences outside the classroom around whether and how their peers and school staff respect their ideas influence how they interact in the classroom. Similarly, teachers' experiences outside the classroom, including whether and how they interact with colleagues, influence their classroom interactions with students. For example, teachers can learn about instruction from their peers but whether they do depends on things such as school norms (e.g., academic press, relational trust, collective responsibility) and organizational arrangements (e.g., organizational routines, scheduling, etc.) $[53,54]$.

My goal here is not to anoint any one theoretical tradition as the chosen way, but rather to illustrate the importance of conceptual work to our empirical investigations and show how tools from various theoretical traditions might be used to frame research on relations between school administration and classroom instruction.

\section{Conceptualizing Relations between School Administrative Practice and Instructional Practice}

Conceptualizing both school administration and instruction from a distributed perspective, underscoring that practice is stretched over people and their situation, constrains how we frame research to investigate relations between them in several ways. In Figure 3 and below, I sketch a conceptual framework for thinking about these relations. I say sketch because while my particular conceptualizations of administrative practice and instructional practice constrain how we might frame relations among them, they do not determine it. A sketch provides a rough description, outlining the contours of these relations while allowing for specification in future work. It is suggestive rather than prescriptive.

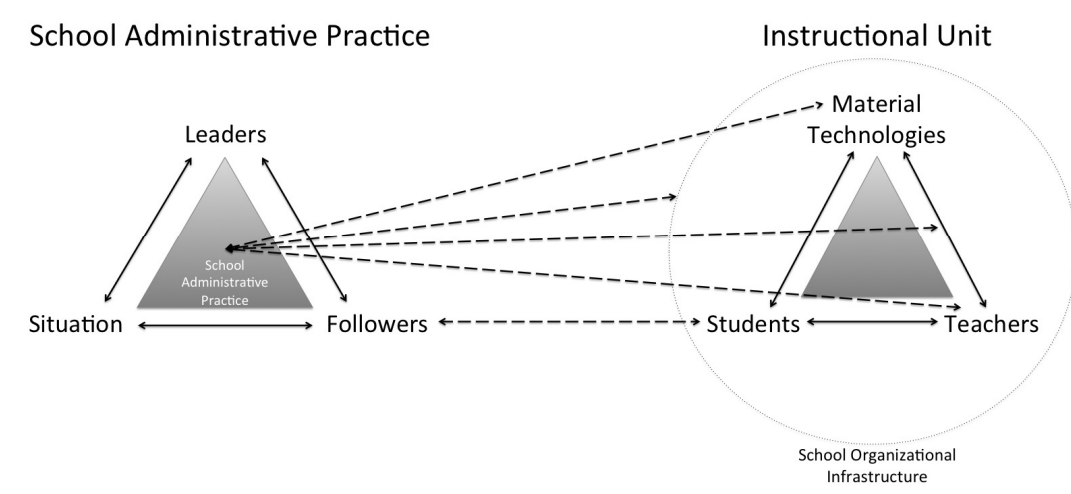

Figure 3. Relationship between School Administrative Practice and Instructional Practice.

To begin with, in conceptualizing school administration and instruction as distributed practices, it follows that efforts to understand relations between the two phenomena is fundamentally about examining relations among two core school practices or systems of practice. Further, these two practices are not independent of one another. Key elements of the instructional unit, especially teachers and students, are also key constituting elements of school administrative practice. As several readers will appreciate, this interdependence poses particular challenges for scholars interested in estimating the effects of school administrative practice on instructional practice. Further, relations between school administrative and instructional practice are bidirectional rather than unidirectional as captured in the two-way arrows in Figure 3. On the one hand, the three key elements of the instructional unit are the object or outcome of interest when studying the influence of school administration on instruction. 
At the same time, elements of the instructional unit are key constituting elements of school administrative practice. For example, depending on the situation teachers are key constituting elements of both instructional practice and of school administrative practice.

Mindful of these observations, I organize my discussion of conceptualizing relations between instructional practice and school administrative practice below around two themes. First, I consider direct and indirect pathways between administrative practice and instructional practice. Second, I outline a framework for thinking about how administrative practice might influence instructional practice through these pathways attending to what dimensions of practice might be influenced and the social mechanisms that might be at play.

\subsection{Administrative Practice and Instructional Practice Relations}

Keeping in mind the core constituting elements of both administrative practice and instructional practice, we can sketch several possible pathways by which administration and instruction might relate [13]. First, school administrative practice might relate chiefly to any one element of the instructional unit. For example, school administrative practice as captured in the performance of a school organizational routine such as a school assembly might focus on motivating students to take their mathematics learning seriously by recognizing exemplary academic performance or improvement in performance over time. Similarly, school administrative practice might encourage and reward teacher performance by recognizing and praising particular staff for exemplary classroom work. Second, school administrative practice might relate directly to two, rather than one, element of the instructional unit, attending simultaneously to teacher and student, teacher and materials, and student and materials. For example, a lesson plan review routine where the school principal or grade level team regularly reviews the lesson plans teachers purport to use, which is common in some schools and school systems, focuses mostly on teacher and materials.

Third, school administrative practice might relate directly to all three elements of the instructional unit, attending simultaneously to teacher, students, and materials. Consider by way of example the Writing Folder Review Routine at Hillside Elementary in Chicago [55,56]. This organizational routine, designed to improve the quality of writing instruction at Hillside, involved a monthly review of students' writing folders. Each month, teachers sent students' writing folders along with their evaluations of the students' work to their principal for that month. The principal read the folders, providing written feedback to both students and teachers, recognizing exemplary work, identifying areas in need of improvement and offering suggestions for addressing these improvement needs. In the design and performance of the Writing Folder Review routine, we observe school administrative practice relating to all three elements of the instructional unit simultaneously. Specifically, the Writing Folder Review Routine connected administrative practice with teachers, students, and material simultaneously as the principal provided students with feedback on their writing and teachers with feedback about their writing instruction.

Similarly, teacher evaluation or supervision routines can, depending on their design and performance, address all three elements of the instructional unit. If the observer attends to not only what the teacher does, but also what students do, and the material under discussion. Learning Walk and Lesson Study routines also tend to focus on all three elements of the instructional unit together though the extent to which they do depends in important measure on their design and ultimately on their 
performance on the ground: Some elements of the instructional unit such as what the teacher does, the quality of the students' intellectual work, or the academic content can be privileged over other aspects in design and/or in performance of organizational routines such as lesson study, learning walks, and teacher supervisions.

We might hypothesize that school administrative practice that engages more elements of the instructional unit are likely to have a stronger influence on instructional practice than administrative practice that engages fewer elements [48]. Motivating students and teachers about the same intellectual material, for example, more than likely increases the influence of the writing folder routine on instruction than if the routine had targeted only one element of the instructional unit. Imagine if school leaders had designed a different organizational routine, such as regularly reviewing teacher lesson plans for writing; administrative practice would have focused mostly on teachers and materials, just two elements of the instructional unit.

Acknowledging these different pathways, we might conceptualize the directness of relations between school administrative practice and instructional practice in at least two ways. First, we might consider relations that involve more elements of the instructional unit as being more direct as they simultaneously engage more constituting elements of instruction. We might hypothesize then that administrative practice that related to all three elements (i.e., teacher, student, and materials) of the instructional unit simultaneously and coherently are likely to have a more potent influence on instruction than administrative practice that focuses on a single element. Second, we might argue that administrative practice that relates directly to the actual performance of instruction by directly observing it (e.g., Learning Walks, teacher supervision or evaluation) involve a more direct relation than administrative practice that relates indirectly (e.g., reviewing teachers' lesson plans). Framing relations between school administration and instruction in this way underscores that direct relations between school administration and instruction can take multiple forms and that the degree of directness is not simply a function of being up close and in the classroom.

My discussion to this point has focused on direct relations between administrative practice and instructional practice. Relations between the two practices, however, may also be indirect in that they focus on what is referred to in the depiction of the instructional unit in Figure 2 as "context". In Figure 3, I use "school organizational infrastructure" instead of context and confine my discussion to the school infrastructure rather than the school system infrastructure more broadly [57,58]. Figure 3 frames administrative practice that focuses on designing, redesigning, and maintaining the school organizational infrastructure as having an indirect relationship with instructional practice. These indirect relations may be just as influential on instruction as direct relations in that they can create conditions that enable teachers to improve their teaching practice by learning from one another, among other things.

\subsection{Influencing What, by What Means}

Identifying the various pathways through which relations between school administrative practice and instructional practice might operate get us only so far, especially if we are intent on doing something more than measuring the effects of administrative practice on instructional practice. To better specify relations between school administrative practice and instructional practice it is necessary 
to elaborate both on what aspects of practice are being influenced and the mechanisms through which this influence is (intended to and actually) exercised.

To begin, we can think about social practice in terms of four interrelated analytical dimensions - cognitive, affective, motivational, and behavioral. Though analytically separate, in practice these dimensions work in interaction [59]. Conceptualizing relations between administrative practice and instructional practice, then, we can examine what combination of cognitive, affective, motivational, and behavioral dimensions is the focus. Teachers' will or motivation and skill are critical to the quality of instructional practice. Similarly, students' motivation and their knowledge and skill fundamentally shape the quality of instructional practice. But the affective and behavioral dimensions are also key. If teachers and students are unable to put their will and skill into practice, it curtails the quality of instructional practice. At the same time, if teachers or students are afraid or feel threatened it curtails the quality of instructional practice.

Some administrative practice, for example, such as publicly recognizing exemplary work on the part of students or teachers foregrounds the motivational dimension, though it might also attend to the cognitive dimension by letting other students see what good work looks like. Similarly, the Writing Folder Review routine described above focuses mostly on motivational and cognitive dimensions of instructional practice by encouraging teachers to teach writing, motivating students to write well, and providing teachers with feedback on what to teach. Other administrative practice such as the performance of a professional learning community routine might simultaneously focus cognitive, motivational, and affective dimensions of instructional practice by providing teachers with opportunities to learn from colleagues, being motivated to improve through interactions with peers, and creating a sense of security among teachers especially as they engage in instructional change.

Here again it is important to acknowledge the bidirectional nature of relations between school administrative practice and instructional practice. Specifically, the affective, motivational, and cognitive dimensions of instructional practice can shape administrative practice. When teachers or students are not motivated to learn and improve the nature of school administrative practice is likely to look different than in situations when they are motivated to learn and improve. Similarly, when teachers and students feel secure, the nature of administrative practice is likely to be different than in situations where they feel threatened.

A second issue concerns what mechanism (or combination of mechanisms) are mobilized through these pathways and might account for school administrative practice influencing instructional practice. It is one thing to show a relationship between school administrative practice and instructional practice and to identify possible pathways for this relationship, but another matter to explain what brought about the association. A key challenge involves explicating the social mechanisms that account for observed associations between administrative practice and instructional practice. How does administrative practice influence (enable and constrain) instructional practice? Addressing this challenge is essential for research intent on establishing causal links as well as identifying the mechanisms at work.

One way (there are others) to conceptualize the means by which school administrative practice influences instructional practice is to borrow from new institutional theorists who identify three ways in which institutions structure practice-regulative, normative, and cultural-cognitive [60]. The regulative dimension refers to procedures, guidelines, and rules specifying what school leaders 
and teachers are required to do. School policy or rules might require that teachers to attend weekly grade level meetings to plan instruction. Rules, guidelines, and procedures (both school and school system) for instructional practice are created, enacted and enforced through school administrative practice. These regulations are designed to structure instructional practice, help maintain instructional quality, and lead instructional improvement. The regulative dimension can address any combination of elements of the instructional unit such as what content should be taught to students of a particular age, who can teach, and even how to engage students with particular subjects (e.g., instructional strategies). School administrative practice can involve the use of formal authority (e.g., positional authority) but also other means such as persuasion to manage instructional quality and lead instructional improvement.

The normative dimension refers to norms and values that create expectations and obligations for particular roles such as teacher, student, and school principal among organizational members and school stakeholders. The normative dimension, for example, might include norms that value (or not) collaboration and the exchange of instructional information among teachers. The normative dimension can establish expectations and obligations for both in classroom and out of classroom practice related to instruction. In some schools and school systems, for example, a norm of privacy prevails with the expectation that the classroom is the teacher's domain. In contrast, in other schools and school systems instruction is a public practice with the expectation that teachers share instructional ideas and knowledge with one another. School administrative practice can both maintain norms and work to transform them through various means including hiring and socializing new school staff members.

The cultural-cognitive dimension centers on sense making, including the scripts and belief systems organizational members construct and use for everyday practice. "A cultural cognitive conception of institutions stresses the central role played by the socially mediated construction of a common framework of meanings" [61]. It centers on school leaders', teachers', and students' (along with school stakeholders') schema for understanding key aspects of their work including instruction, instructional improvement, learning, and achievement. For example, schemas for understanding academic performance may be predominantly ability-based or effort-based and, depending on which conceptualization prevails, have a profound influence on instructional practice as well as efforts to improve that practice.

Regulative, normative, and cultural-cognitive dimensions work in interaction rather than in isolation [61]. For example, teachers, school leaders, and students negotiate and interpret rules and regulations as they implement them so the influence of these rules cannot be explained entirely by the regulative dimension; it also necessitates attention to the cultural-cognitive dimension that influences the sense-making process and indeed the normative aspect that legitimates whose meanings carry weight.

Using the regulative, normative, and cultural-cognitive framework, we can begin to specify the mechanisms at work in the various pathways between administrative practice and instructional practice. These mechanisms operate in at least one of two ways. First, participants in administrative practice can marshal norms, regulations, and cultural-cognitive beliefs in an effort to influence one another. A coach or teacher leader, for example, might appeal to shared values or norms to persuade colleagues of the merit of a new curriculum, using a particular mathematics pedagogical strategy, or an approach to building pedagogical content knowledge among school staff. Similarly, a school principal might directly or indirectly appeal to rules and regulations such as the positional authority of the 
principal position or some external agent or agency (e.g., school district, state) — as she/he negotiates with school staff about changing current practice (e.g., participating in weekly meetings to discuss instructional practice, getting students to justify their answers to mathematical problems).

We might think about these uses of norms, regulations, and beliefs in practice as social tactics [62]. Based on the literature on strategic social action [63-66], Fligstein [62] theorizes a range of tactics that "socially skilled actors" use to persuade others and gain cooperation. These include: telling people what to do; agenda-setting; capitalizing on ambiguities and uncertainties; convincing others that what was possible was preferable; brokering; giving the impression of neutrality; joining groups to reorder preferences; getting others to believe that they are in control (even if they are not); and creating alliances and outliers. This list is not meant to be exhaustive, but to give a sense of the tactics that school leaders (e.g., including formal and informal teacher leaders) might use to gain cooperation of colleagues [67].

While norms, regulations, and cultural-cognitive beliefs might be deployed directly in administrative practice in an effort to persuade school staff to change their instructional practice and maintain instructional quality, they can also be used indirectly to influence instructional practice. Specifically, school administrative practice might work to influence instructional practice by transforming the school's normative, regulative, and cultural-cognitive dimensions. By working to transform school norms (e.g., building norms of collaboration about instruction to replace norms of privacy), school administrative practice can influence instructional practice as teachers are more likely to learn from their peers when norms of collaboration, rather than norms of privacy, prevail in a school. Similarly, school administrative practice can transform school regulations and monitor their implementation so that teachers interact with one another about instruction regularly. In turn, these changes can potentially over time result in teachers learning from their peers and improving their practice.

To summarize tentatively, identifying the pathways between school administrative practice and instructional practice gets us only so far. We also need to conceptualize what aspects of practice are being influenced and the intended and actual mechanisms at play in practice.

\section{From Conceptualizing Relations to Study Operations and Measures}

This paper has focused chiefly on conceptualizing relations among school administrative practice and instructional practice. This is of course just the first step in designing research to examine relations between school administration and instruction, though an essential and necessary first step because absent careful conceptualization our empirical observations are fatally flawed. While some recent work has attended explicitly to study operations when using a distributed perspective, more work is necessary $[14,68,69]$. At the same time, we have to move beyond conceptualization work to consider study operations and develop measures. I briefly address the issue in this section.

Developing study operations is especially critical for translating theoretical and analytical ideas into measures for data collection and analysis, enabling the distributed framework to be used systematically in research studies. By "study operation" we mean the definition and specification of an aspect of a conceptual or analytical framework so that it can be measured based on observations in the field. For example, the operationalization of theoretical or analytical ideas in the distributed perspective on school administration has received limited attention to date, with a handful of exceptions. This work will involve developing study operations and "measures" of different aspects of school leadership and management when viewed through a distributed perspective [70,71]. Such work is essential so that the 
field moves beyond relying chiefly on repackaging or re-labeling existing measures to fit with a distributed perspective. While we can, and indeed should, salvage existing measures where possible in applying a distributed perspective, an exclusive focus on salvaged measures runs the risk of a distributed perspective becoming simply a new label for old and familiar constructs. The same holds for conceptualizing instructional practice from a distributed perspective.

\section{Discussion and Conclusion}

Conceptualization work, along with developing study operations and measures, and instrument development will determine to a great extent the ultimate quality of any effort to study relations between school administrative practice, framed from a distributed perspective, and instructional practice, the most proximal cause of student achievement. Fancy statistical methods, or even random assignment study designs, cannot compensate for loose constructs, weak study operations and invalid and unreliable measurement. I focused my conceptual work on practice; that is, school administrative practice and instructional practice. I do so for two reasons. First, practice is ultimately where school administration and instruction connect. Second, if our research is to be useful and usable for policymakers and practitioners, it has to speak more directly to practice.

A key argument in this paper is that our conceptualization of both administrative practice and the instructional practice will (should) fundamentally shape how we study relations between the two. Though this is research design 101, it is something that is too frequently ignored or left implicit in the dialogue about how best to study the effects of school administration on classroom instruction and by extension student learning, where questions of study design (e.g., randomization or regression discontinuity study design), measurement (e.g., the stability of Value Added Measures), and statistical models garner most of the attention. Such matters are of fundamental importance but they all ultimately depend on good measurement of the phenomena under study and in turn that depends on careful conceptualization of the phenomena and how they might relate to one another.

While I believe that conceptualizing both administration and instruction from a distributed perspective has several affordances, my point is not that the distributed conceptualization advanced here is the one best way to conceptualize the phenomena. It is one way, and a way that I think has several affordances, especially if practice is a central consideration. More broadly, my argument is that conceptualization work in general is critical to conducting more rigorous theory building and theory testing research on relations between school administration, instruction, and student outcomes. Let's rise to the occasion as a field.

\section{Acknowledgements}

This paper has benefited tremendously from several collaborative writing projects over the past decade. In particular papers with Kaleen Healey, Karen Seashore Louis, and Mary Kay Stein [70,72,73]. Work on this article was supported by the Distributed Leadership Studies (http:// www.distributedleadership.org) funded by research grants from the National Science Foundation (REC-9873583, RETA Grant \# EHR-0412510), the Institute for Education Sciences (Grant \# R305E040085), and the Spencer Foundation (200000039).Northwestern University's School of Education and Social Policy and Institute for Policy Research supported this work. All opinions and 
conclusions expressed in this article are those of the authors and do not necessarily reflect the views of any funding agency.

\section{Conflicts of Interest}

The author declares no conflict of interest.

\section{References}

1. Bryk, A.S.; Sebring, P.; Allensworth, E.; Luppescu, S.; Easton, J.Q. Organizing Schools for Improvement: Lessons from Chicago; University of Chicago Press: Chicago, IL, USA, 2009.

2. Grissom, J.A.; Loeb, S. Triangulating principal effectiveness: How perspectives of parents, teachers, and assistant principals identify the central importance of managerial skills. Am. Educ. Res. J. 2011, 48, 1091-1123.

3. Hallinger, P.; Heck, R.H. The principal's role in school effectiveness: A review of methodological issues. In The International Handbook of Educational Leadership and Administration; Leithwood, K.A., Ed.; Kluwer: Dordrecht, The Netherlands, 1996.

4. Heck, R.H.; Hallinger, P. Next generation methods for the study of leadership and school improvement. In Handbook of Research on Educational Administration; Murphy, J., Louis, K.S., Eds.; Jossey-Bass: San Francisco, CA, USA, 1999.

5. Leithwood, K.A.; Louis, K.S.; Anderson, S.; Wahlstrom, K. How Leadership Influences Student Learning: A Review of Research for the Learning from Leadership Project; The Wallace Foundation: New York, NY, USA, 2004.

6. Louis, K.S.; Kruse, S.D. Professionalism and Community: Perspectives on Reforming Urban Schools; Corwin Press: Newbury Park, CA, USA, 1995.

7. Newmann, F.M.; Wehlage, G.G. Successful School Restructuring: A Report to the Public and Educators; Center on Organization and Restructuring of Schools: Madison, WI, USA, 1995.

8. Purkey, S.C.; Smith, M.S. Effective schools: A review. Elem. Sch. J. 1983, 83, 426-452.

9. Robinson, V.M.J.; Lloyd, C.A.; Rowe, K.J. The impact of leadership on student outcomes: An analysis of the differential effects of leadership types. Educ. Adm. Q. 2008, 44, 635-674.

10. Rosenholtz, S.J. Workplace conditions that affect teacher quality and commitment: Implications for teacher induction programs. Elem. Sch. J. 1989, 89, 421-439.

11. Silins, H.; Mulford, B. Schools as learning organisations: The case for system, teacher and student learning. J. Educ. Adm. 2002, 40, 425-446.

12. Gronn, P. Distributed leadership as a unit of analysis. Leadersh. Q. 2002, 13, 423-451.

13. Leithwood, K.A.; Mascall, B.; Strauss, T.; Sacks, R.; Memon, N.; Yashkina, A. Distributing leadership to make schools smarter: Taking the ego out of the system. Leadersh. Policy Sch. 2007, $6,37-67$.

14. Camburn, E.M.; Rowan, B.; Taylor, J.E. Distributed leadership in schools: The case of elementary schools adopting comprehensive school reform models. Educ. Eval. Policy Anal. 2003, 25, 347-373.

15. Lester, F.K. On the theoretical, conceptual, and philosophical foundations for research in mathematics education. ZDM 2005, 37, 457-467. 
16. Eisenhart, M. Conceptual frameworks for research circa 1991: Ideas from a cultural anthropologist; implications for mathematics education researchers. In Proceedings of the 13th Annual Meeting of the North American Chapter of the International Group for the Psychology of Mathematics Education; Blacksburg, VA, USA, 16-19 October 1991; Psychology of Mathematics Education: Blacksburg, VA, USA, 1991; Volume 1, pp. 202-219.

17. Cohen, D.K. Teaching and Its Predicaments; Harvard College: Cambridge, MA, USA, 2011.

18. Gonzalez, N.; Moll, L.C.; Amanti, C. Funds of Knowledge: Theorizing Practices in Households, Communities, and Classrooms; Lawrence Erlbaum: Mahwah, NJ, USA, 2005.

19. Moll, L.C. Some key issues in teaching latino students. Lang. Arts 1988, 65, 465-472.

20. López, A.; Correa-Chávez, M.; Rogoff, B.; Gutierrez, K.D. Attention to instruction directed to another by us mexican-heritage children of varying cultural backgrounds. Dev. Psychol. 2010, 46, 593-601.

21. Gutierrez, K.D.; Vossoughi, S. Lifting off the ground to return anew: Mediated praxis, transformative learning, and social design experiments. J. Teah. Educ. 2009, 61, 100-117.

22. Rosenthal, R.; Jacobson, L. Pygmalion in the classroom. Urban Rev. 1968, 3, 16-20.

23. Becker, H.S. Social-class variations in the teacher-pupil relationship. J. Educ. Sociol. 1952, 25, 451-465.

24. Cuban, L. The Managerial Imperative and the Practice of Leadership in Schools; SUNY Press: Albany, NY, USA, 1988.

25. Bass, B.M. Bass \& Stogdill's Handbook of Leadership: Theory, Research, and Managerial Applications; Free Press: New York, NY, USA, 1990.

26. Spillane, J.P.; Diamond, J.B. Distributed Leadership in Practice; Teachers College Press: New York, NY, USA, 2007.

27. Gronn, P. Distributed properties: A new architecture for leadership. Educ. Manag. Adm. Leadersh. 2000, 28, 317-338.

28. Spillane, J.P.; Halverson, R.; Diamond, J.B. Investigating school leadership practice: A distributed perspective. Educ. Res. 2001, 30, 23-28.

29. Spillane, J.P. Distributed Leadership; Jossey-Bass: San Francisco, CA, USA, 2006.

30. Hutchins, E. How a cockpit remembers its speeds. Cogn. Sci. 1995, 19, 265-288.

31. Lave, J.; Wenger, E. Situated Learning: Legitimate Peripheral Participation; Cambridge University Press: New York, NY, USA, 1991.

32. Rogoff, B. The Cultural Nature of Human Development; Oxford University Press: New York, NY, USA, 2003.

33. Cole, M.; Engeström, Y. A cultural-historical approach to distributed cognition. In Distributed Cognitions: Psychological and Educational Considerations; Salomon, G., Ed; Cambridge University Press: Cambridge, UK, 1993.

34. Wertsch, J.V. A sociocultural approach to socially shared cognition. In Perspectives on Socially Shared Cognition; Resnick, L.B., Levine, J.M., Teasley, S.D., Eds.; American Psychological Association: Washington, DC, USA, 1991.

35. Simmel, G. Conflict and the Web of Group Affiliations; The Free Press: New York, NY, USA, 1955.

36. Fiedler, F.E. A Theory of Leadership Effectiveness; McGraw-Hill: New York, NY, USA, 1967; Volume III. 
37. Hemphill, J.K. The leader and his group. Educ. Res. Bulletin 1949, 28, 225-229.

38. Dahl, R.A. Who Governs? Democracy and Power in an American City; Yale University Press: New Haven, CT, USA, 1961.

39. Suchman, L.A. Plans and Situated Actions: The Problem of Human-machine Communication; Cambridge University Press: Cambridge, MA, USA, 1987.

40. Harris, A. Leading or misleading? Distributed leadership and school improvement. J. Curriculum Stud. 2005, 37, 255-265.

41. MacBeath, J.; Oduro, G.K.T.; Waterhouse, J. Distributed Leadership in Action: A Study of Current Practice in Schools; National College for School Leadership: Nottingham, UK, 2004.

42. Dunkin, M.J.; Biddle, B. The Study of Teaching; Rinehart and Windston: New York, NY, USA, 1974.

43. Mitzel, H.E. Teacher effectiveness. In Encyclopedia of Educational Research, 3rd ed.; Harris, C.W., Ed.; Macmillan: New York, NY, USA, 1960; pp. 1481-1486.

44. Brophy, J.E. Advances in Research in Teaching: Subject-Specific Instructional Methods and Activities; Elsevier Science: Oxford, UK, 2001; Volume 8.

45. Gage, N. The Scientific Basis of the Art of Teaching; Teachers College Press: New York, NY, USA, 1978.

46. Gage, N.; Giaconia, R. Teaching practices and student achievement: Causal connections. N. $Y$. Univ. Educ. Q. 1981, 12, 2-9.

47. Good, T.; Grouws, D.; Ebmeier, H. Active Mathematics Teaching; Longman: New York, NY, USA, 1983.

48. Cohen, D.K.; Ball, D.L. Instruction, Capacity, and Improvement; Consortium for Policy Research in Education: Philadelphia, PA, USA, 1999.

49. Delpit, L. Other People's Children: Cultural Conflict in the Classroom; New Press: New York, NY, USA, 1995.

50. Doyle, W. Academic work. Rev. Educ. Res. 1983, 53, 159-199.

51. Hawkins, D. I, thou, and it. In The Informed Vision: Essays on Learning and Human Nature; Hawkins, D., Ed.; Agathon: New York, NY, USA, 1967; pp. 48-62.

52. Jackson, P.W. Life in Classrooms; Holt, Rinehart, and Winston: New York, NY, USA, 1968.

53. Jackson, K.; Bruegmann, E. Teaching students and teaching each other: The importance of peer learning for teachers. Am. Econ. J.: Appl. Econ. 2009, 1, 85-108.

54. Sebring, P.; Allensworth, E.; Bryk, A.S.; Easton, J.Q.; Luppescu, S. The Essential Supports for School Improvement; Consortium on Chicago School Research: Chicago, IL, USA, 2006.

55. Coldren, A.F. Spanning the boundary between school leadership and classroom instruction at hillside elementary school. In Distributed Leadership in Practice; Spillane, J.P.; Diamond, J.B., Eds.; Teachers College Press: New York, NY, USA, 2007; pp. 16-34.

56. Spillane, J.P.; Coldren, A.F. Diagnosis and Design for School Improvement: Using a Distributed Perspective to Lead and Manage Change; Teachers College Press: New York, NY, USA, 2011.

57. Cohen, D.K.; Moffitt, S.L. The Ordeal of Equality: Did federal Regulation Fix the Schools? Harvard University Press: Cambridge, MA, USA, 2009.

58. Cohen, D.K.; Peurach, D.; Glazer, J.L.; Gates, K.E.; Goldin, S. Improvement by Design: The Promise of Better Schools; University of Chicago Press: Chicago, IL, USA, 2013. 
59. Marris, P. Loss and Change; Routledge \& Kegan Paul: London, UK, 1974.

60. Scott, W.R. Approaching adulthood: The maturing of institutional theory. Theory Soc. 2008, 37, 427-442.

61. Scott, W.R. Institutions and Organizations: Ideas, Interests, and Identities, 4th ed.; Sage: Thousand Oaks, CA, USA, 2014.

62. Fligstein, N. The Architecture of Markets; Princeton University Press: Princeton, NJ, USA, 2001.

63. Gould, R. Collective action and network analysis. Am. Sociol. Rev. 1993, 58, 182-196.

64. Lukes, S. Power: A Radical View; Macmillan: London, UK, 1974.

65. Padgett, J.; Ansell, C. Robust action and the rise of the medici. Am. J. of Sociol. 1992, 98, 1259-1320.

66. Snow, D.A.; Benford, R.D. Master frames and cycles of protest. In Frontiers in Social Movement Theory; Morris, A.D., Mueller, C.M., Eds.; Yale University: New Haven, CT, USA, 1992.

67. Spillane, J.P.; Anderson, L.M. Administration des écoles, respect des normes gouvernementales, et obligation de résultats à forts enjeux: Changement politique et pédagogique aux états-unis. Educ. Soc. 2013, 32, 53-73.

68. Spillane, J.P.; Camburn, E.M.; Pareja, A.S. Taking a distributed perspective to the school principal's workday. Leadersh. Policy Sch. 2007, 6, 103-125.

69. Spillane, J.P.; Hunt, B.; Healey, K. Managing and leading elementary schools: Attending to the formal and informal organisation. Int. Stud. Educ. Adm. 2009, 37, 5-28.

70. Spillane, J.P.; Healey, K. Conceptualizing school leadership and management from a distributed perspective. Elem. Sch. J. 2010, 111, 253-281.

71. Spillane, J.P.; Healey, K.; Kim, C.M. Leading and managing instruction: Using social network analysis to explore formal and informal aspects of the elementary school organization. In Social Network Theory and Educational Change; Daly, A.J., Ed.; Harvard Education Press: Cambridge, MA, USA, 2010; pp. 129-156.

72. Spillane, J.P.; Louis, K.S. School improvement processes and practices: Professional learning for building instructional capacity. Yearb. Natl. Soc. Stud. Educ. 2002, 101, 83-104.

73. Stein, M.K.; Spillane, J.P. What can researchers on educational leadership learn from research on teaching? Building a bridge. In A New Agenda for Research in Educational Leadership; Firestone, W.A., Riehl, C., Eds.; Teachers College Press: New York, NY, USA, 2005; pp. $28-45$.

(C) 2015 by the author; licensee MDPI, Basel, Switzerland. This article is an open access article distributed under the terms and conditions of the Creative Commons Attribution license (http://creativecommons.org/licenses/by/4.0/). 